\title{
Cognitive Vulnerability Predictive Factors For Depression In Adolescence
}

\author{
Lence Miloseva ${ }^{1}$, Dijana Miloseva ${ }^{2}$ \\ ${ }^{1}$ Faculty of Medical Sciences- Goce Delcev University-Stip, North Macedonia \\ 2 Medical faculty- UKIM- Skopje, North Macedonia
}

\section{Objectives:}

The main objective is to investigate and determine the role and relationship of predictive risk factors and clinical and subclinical depression within the Cognitive Vulnerability-Transactional stress model of depression (Hankin and Abramson, 2002).

\section{Background:}

Within the Cognitive Vulnerability-Transactional stress model of depression in adolescence, there is a significant association between cognitive vulnerability predictive risk factors of depression, and the level of symptoms of depression.

\section{Materials and Methods:}

The research was conducted in clinics and schools in the three main centers of socio-demographic regions in North Macedonia (Skopje, Stip, Bitola). The sample consisted of: the clinical group 139 (33.7\%); the subclinical group, 133 (32.3\%) and 140 $(34.0 \%)$ respondents in control group, aged 13-17 years. Predictive factors for depression were measured by a set of instruments. We applied: Data sheet for all respondents; M.I.N.I. Interview (MINI kid Screen /DSM-IV-TR); Dysfunctional Attitude Scale (DAS, Weissman \& Beck, 1978); Adolescent's Cognitive Style Questionnaire (ASCQ); Ruminative Response Style Questionnaire (RSQ); Adolescent Life Events Questionnaire (ALEQ); Multidimensional Scale of Perceived Social Support (MPSS) and Beck Depression Inventory II (BDII). All respondents completed the same set of instruments that we used for this study.

\section{Results and Conclusions:}

When the predictive model of depression in adolescence was built solely on the basis of risk factors for cognitive vulnerability, negative life events and their interaction, the analysis showed that there was significant prediction of depression levels in predictive models of the clinical group $(62.5 \%)$, the subclinical group $(63.3 \%)$ and the control group (65.9\%).

In the predictive model of the clinical group, ruminative response style has the role of the strongest predictor of levels of depression symptoms, and the lowest are negative life events. In the predictive model of the subclinical group the strongest significant predictors are dysfunctional attitudes, and the weakest is the interaction between negative life events and dysfunctional attitudes. The analysis of the results in the control group singled out the negative inferential style as the strongest predictor, and the weakest is the ruminative response style. The confirmation of the diathesis-stress model is the finding that the interaction between dysfunctional attitudes and negative life events in the subclinical group contributes to predicting levels of depression

\begin{tabular}{|c|c|c|c|c|c|}
\hline Group & & $\beta$ & $\mathbf{t}$ & p & $r$ \\
\hline \multirow[t]{5}{*}{ Clinical } & & & & & \\
\hline & RUM_ortog & .444 & 7.859 & .000 & .427 \\
\hline & DAS_ortog & .394 & 7.293 & .000 & .391 \\
\hline & ACSQ_ortog & .373 & 6.945 & .000 & .379 \\
\hline & ALEQ_ortog & .366 & 6.156 & .000 & .378 \\
\hline \multirow[t]{6}{*}{ Subclinical } & & & & & \\
\hline & RUM_ortog & .295 & 5.327 & .000 & .314 \\
\hline & DAS_ortog & .443 & 8.046 & .000 & .456 \\
\hline & ACSQ_ortog & .337 & 5.749 & .000 & .325 \\
\hline & ALEQ_ortog & .437 & 8.057 & .000 & .444 \\
\hline & $\begin{array}{l}\text { ALEQ_DAS_ } \\
\text { interac_ortog }\end{array}$ & .115 & 2.045 & .043 & .181 \\
\hline \multirow[t]{5}{*}{ Control } & & & & & \\
\hline & RUM_ortog & .340 & 6.639 & .000 & .340 \\
\hline & DAS_ortog & .408 & 7.841 & .000 & .396 \\
\hline & ACSQ_ortog & .506 & 9.907 & .000 & .505 \\
\hline & ALEQ_ortog & .354 & 6.933 & .000 & .358 \\
\hline
\end{tabular}

Table 1: Significant predictors in clinical, subclinical and control group in the table of regression coefficients

Abela, J.R.Z., \& Hankin, B.L. (Eds). (2008). Handbook of Child and Adolescent Depression. New York, NY:

Guilford Press Hankin, B. L., \& Abramson, L. Y. (2002). Measuring cognitive vulnerability to depression in adolescence:

Reliability, validity, and gender differences. Journal of Child \& Adolescent Clinical Psychology, 31, 491-504.

Miloseva, L. (2017). Depression in adolescence: Screening, Prevention and Treatment from Cognitive Behavioral Perspective. Stip: University Goce Delcev- Stip. 